Parallaxes of Procyon and Altair.-Among the large number of stellar parallaxes recently determined by photographic methods at the Leander McCormick Observatory, Dr. S. A. Mitchell has directed special attention to the results for Procyon and Altair (Pop. Ast, vol. xxv., p. 38 ). For Procyon, the values which have been previously determined are remarkably consistent, ranging from $0.287^{\prime \prime}$ to $0.34^{\prime \prime}$, and Dr. Mitchell's parallax of $0.309^{\prime \prime} \pm 0.007^{\prime \prime}$ is in perfect agreement with the mean of all. The parallax arrived at for Altair is $0.218^{\prime \prime} \pm 0.007^{\prime \prime}$, and this again accords very closely with the weighted mean value $0.220^{\prime \prime}$ derived from earlier determinations.

Densities of Visual Binary Stars.-An interesting attempt to advance our knowledge of the densities of stars of different classes has been made by E. Öpik, of Moscow, in a discussion of the probable densities of visual binaries for which orbits have been calculated (Astrophysical Journal, xliv., p. 292). He proceeds by developing a series of formulæ by which the density can be determined when the surface brightnesses of the components are known. The surface brightness itself is determined from the spectral type, in conjunction with the corresponding effective temperatures given by Wilsing and Scheiner, and an application of the radiation formula of Planck. The mass-ratio of the two components must also be known, and where such data are not available, approximate values are estimated from the differences in magnitude. The densities calculated in this way for forty pairs cover a wide range (0.012 to 5.9 , in terms of the sun), but a considerable proportion of them approach the density of the sun. The mean values for the different spectral classes, which are only to be regarded as roughly approximate, are as follows :-

\begin{tabular}{cccrcc} 
Spectral type & & \multicolumn{3}{c}{ No. of stars } & Density \\
A o-A 5 & $\ldots$ & $\ldots$ & 9 & $\ldots$ & 0.65 \\
F o-F 8 & $\ldots$ & $\ldots$ & r9 & $\ldots$ & 0.59 \\
G $\ldots$ & $\ldots$ & $\ldots$ & 7 & $\ldots$ & 0.23 \\
K, K $_{5}$ & $\ldots$ & $\ldots$ & 5 & $\ldots$ & 0.072
\end{tabular}

So far as they go, though the author does not comment upon this point, the figures show an order of density opposite to that which would be expected on the supposition that celestial evolution is along a line of descending temperature only. When accurate magnitudes and spectral types (or colour-indices) become available for each component, it will be possible to obtain separately the densities of the components, and an important region of stellar statistics will be opened up.

\section{EXPERIMENTS ON ASCARIS INFECTION IN HONG KONG.}

A $\mathrm{N}$ important paper by Capt. F. H. Stewart, Indian Medical Service, appeared in the British Medical Journal for July I, giving the life-history of Ascaris lumbricoides, which is extremely common both in man and the pig at Hong Kong, where the author is stationed with the $74^{\text {th }}$ Punjabis. In this preliminary communication he showed that the parasite presents an alternation of hosts. Thus, when ripe eggs reach the alimentary canal of the rat or mouse the larvæ are liberated, and six days after infection they are found in the blood-vessels of the lungs and liver, and the host is seriously ill with pneumonia. They next pass from the blood-vessels into the air-vesicles of the lung, causing hæmorrhage into them. On the tenth day they occur only in the vesicles and in the bronchi. If the disease does not prove fatal, the host recovers on the eleventh or twelfth day, whilst on the sixteenth day it is free from parasites. The affected animals could readily contaminate by the nose or mouth the food of man or the dust and earth of his surroundings. Capt. Stewart has continued his experiments since the foregoing date both with $A$. lumbricoides and A. suilla, and finds that the larvæ appear in the bronchi, trachea, and mouth of the rat and mouse on the night of the seventh day and during the eighth day after infection by the mouth, and he believes that they pass by means of the saliva on to the food which is being nibbled by the rodents. It is possible that one attack of Ascariasis in rats renders them immune against subsequent attacks, but further confirmation is necessary. He found that the larvæ survived longest (twenty-four hours) in blood on moist bread. In water, normal salt-solution, and in mouse's blood they survived three hours.

Out of five experiments to test the infection of pigs from the foregoing rodents, three gave positive results, two negative. In estimating the value of the negative experiments the very high mortality among the parasites employed under somewhat unnatural conditions must be kept in mind. Capt. Stewart endeavoured to obtain an estimate of this mortality by comparing the number of ripe eggs given to a mouse with the number of larvæ found in the lung. An average dose contained about 5000 eggs, whilst the number of larvæ found in the lungs did not exceed fifty. The transfer from the rodent to the pig is probably the most vulnerable part of the life-cycle, since the larva is a very delicate organism. The author also carried out control experiments with the pig.

Lastly, Capt. Stewart carried out some experiments which demonstrated that $A$. marginata of the dog has also its intermediate host in the mouse.

$\mathrm{He}$ concludes by stating that if ripe eggs of $A$, lumbricoides are swallowed by rats or mice they hatch. The larvæ bore into the venules of the portal system or ascend the bile-duct. They are found in the dilated capillaries of the liver between the second and the fifth days. As their diameter is three times that of a blood-corpuscle in the mouse, they cannot pass through a normal capillary. The liver-cells in the neighbourhood of the larvæ undergo rapid degeneration, and the larvæ are thus enabled to pass by the hepatic vein and vena cava to the heart, and by the pulmonary artery to the lungs, where they are filtered off at the entrance to the capillary field. Embolism of the arterioles takes place, and the larvæ pass with the effused blood into the air-vesicles on the sixth day. They are found in the bronchi on the seventh day, and in the trachea and mouth on the eighth day, after infection. The larvæ from the lungs of rodents can infect the pig, and it is probable that in Nature infection of both man and the pig takes place by food contaminated by rats and mice. $\quad$ W. C. M.

\section{SEX-LIMITED FACTORS IN HEREDITY.}

$\mathrm{F}$ EW of the results obtained in recent years by students of heredity on Mendelian lines have appealed to biologists as a whole more forcibly than such cases of "sex-limited" inheritance as are exemplified by colour-blindness in mankind or the special type of wing-marking in the magpie-moth (Abraxas grossulariata) described by Dr. Leonard Doncaster in his work on the "Determination of Sex." Those whe have followed the progress of research on the subject during the last five years recognise how important have been the results obtained by Prof. T. H. Morgan and his colleagues in their studies of inheritance in fruit-flies of the genus Drosophila.

An admirable summary of these studies, entitled

NO. 2468, VOL. 98] 